\title{
Rail Transportation Lead Urban Form Change: A Case Study of Beijing
}

\author{
Chun Zhang ${ }^{1} \cdot$ Haishan $\mathrm{Xia}^{1} \cdot$ Yan Song $^{2}$
}

Received: 20 January 2017/Revised: 23 March 2017/Accepted: 25 March 2017/Published online: 13 May 2017

(C) The Author(s) 2017. This article is an open access publication

\begin{abstract}
In the background of rapid urban metro transit construction in China, rail transportation becomes an important factor in shaping urban form. This case study focuses on the urban form changes caused by urban rail transportation development in Beijing and especially explores the synergetic links between urban planning and transportation from the perspective of a transportationpopulation-economy research framework. Based on population census surveys and basic economic unit census surveys on street district level, combined with digital urban metro lines on street district level, findings show that the population spatial distribution tends to disperse along the metro lines, and concentrates around metro network connections. The employment distribution turns to be more concentrated in high accessibility areas around metro intersections. The population and employment distributions indicate a job-housing mismatch, where the employment centers are concentrated in the central city, while residential centers are concentrated in suburban areas. The consequence of this mismatch is that regions with extreme job-housing imbalance also see higher degrees of imbalance in urban metro volume. This paper aims to provide insights on how to improve job accessibility and creating a
\end{abstract}

Chun Zhang and Yan Song: UNC-BJTU Consortium for Urban and Regional Transportation.

Haishan Xia

hshxia@bjtu.edu.cn

1 School of Architecture and Design, Beijing Jiaotong University, Beijing, China

2 Department of City and Regional Planning, University of North Carolina at Chapel Hill, Chapel Hill, NC, USA more sustainable urban form, as well as promoting a synergetic development between urban planning and transportation.

Keywords Urban rail transportation - Urban form · Job accessibility · Job-housing spatial relationship · Beijing

\section{Introduction}

In the second half of the twentieth century, metropolitan urban forms changed dramatically massive investments in transportation infrastructure. In particular, construction of regional and urban rail transit, including urban light rail and metro system, not only shortens the commuting time of urban residents, but significantly alters urban spatial patterns, such as population and employment distributions. From an urban planning perspective, rail transportation not only brings change in commuting speed, but also entails unprecedented challenges and opportunities for a twentyfirst-century metropolitan development. For example, the European Union initiative Polycentric Metropolitan strategy [1-3], the USA 2050 [4], and several Asian countries promote transportation infrastructure as important factor in supporting sustainable development of metropolitan areas.

Globally, large-scale high-speed rail drives regional metropolitan area changes [5] at the macrolevel, while on a mesoscale urban metro systems also reshape the urban form [6]. In particular, cross-regional transportation infrastructure becomes a key factor in regional cooperation among different administrative jurisdictions. For example, since China's first 5-year plan in the 1950s, national railway construction has represented the nation's advanced industrialization process.

Editors: Haishan Xia and Chun Zhang 
The concept of urban form is not only limited to the Chinese vocabulary "spatial shape," but its wider definition focuses on layout and development patterns from both physical and non-physical aspects [7]. From the perspective of a synergetic development of urban planning and transportation, urban form highlights the interaction between economic factors, population statistics and transportation modes, as well as the potential impact of transportation on the spatial distribution in metropolitan areas The two most widely used indicators to analyze urban form and transportation are job-housing spatial relation and job accessibility.

Previous research on urban form has focused on various aspects, such as transportation efficiency, network configuration and job-housing spatial relationship. For example, Frank and Pivo [8] describe how the four-stage traditional transportation model predicts traffic demand and traffic volume based on traffic analysis zones (TAZs). The key issue for the transportation model is to improve efficiency and mobility of transportation systems [7]. Later, as transportation research shifted toward the urban field, more scholars began to emphasize the job-housing spatial relationship in metropolitan areas, using demographic data to simulate current and future travel behavior [9, 10]. The availability of census data and development of GIS technology support the analysis of population and employment density data in correlation with transportation networks.

Furthermore, since the 1990s, transportation-related problems increasingly became a universal challenge in most metropolitan areas. Both transportation planners and urban planners realized that transportation policies alone are not sufficient to tackle highly complex transportation problems. Instead, the New Urbanism movement and Smart Growth policy in the USA aimed to build a comprehensive analytical framework drawing on a wide range of population, economy, land-use and transportation data. Today in Chinese cities, the rapid growth in urban rail transit development occurs in tandem with a fast urbanization process, posing new, complex problems to transportation planners, urban planners and government officials.

The current literature on urban transportation mainly focuses on traffic model characteristics, accessibility and transportation network efficiency. However, comprehensive studies on the spatial, social and economic impacts of transportation infrastructure are still rare. Against this background, this paper analyzes changes in urban form in the metropolitan area of Beijing. By using street districtlevel GIS data, we especially look into how the rapidly developing rail transit system affects the job-housing spatial relation. Focusing on the interactive relationship between urban rail transit and urban form, this paper will provide policy implications for the synergetic development of transportation, land-use and urban planning in BeijingTianjin-Hebei area.

\section{Literature Review on Transportation Impact on Urban Form}

The current literature on the influence of transportation infrastructure on urban form includes three issues, jobhousing spatial relationship, job accessibility and the relation between urban form and travel behavior.

\subsection{Job-Housing Spatial Relationship}

The issue of job-housing spatial relationship has long been a hot topic and has received wide interest from the urban planning, transportation and sociology field. The spatial mismatch concept originated with Kain [11] who found that while job opportunities in America moved to the suburbs, low-skilled workers continued living in city centers. The original spatial mismatch hypothesis (SMH) has been continuously discussed and challenged in many ways. Some scholars considered it a racial discrimination problem rather than a spatial problem [12] or a language problem [13, 14]. Other scholars have concluded that the mismatch might be caused by differences in travel mode, i.e., car ownership, especially in cities with insufficient public transit systems, such as Detroit [15].

Although transportation technology has greatly improved in recent years, the job-housing mismatch in big cities appears to have worsened [16]. While most research focuses on the job-housing mismatch and related unemployment issues within the city, some case studies provide metropolitan-level analysis. As suburbanization processes provide more employment opportunities in suburban job centers, the urban poor living in the outskirts of cities may face difficulties in accessing jobs due to a lack of public transportation facilities [17]. Thus, the traditional model based on an urban center-suburban binary division might be not sufficient.

The job-housing mismatch in Chinese cities has gained more research attention in recent years. In the planned economy era, the job-housing relationship used to be perfectly balanced on a Work Unit basis, but with the disintegration of Work Units, the job-housing spatial relationship has gradually shifted from a "spatial bond" to "spatial mismatch". In particular, the rapid development of affordable housing in urban fringe locations, while the economic momentum remains in city centers, has led to a widening of the gap between job and housing locations [18]. The rapidly changing job-housing patterns in Chinese cities has drawn attention from both the transportation field 
and the urban planning field, due to the links between urban form and commuting behavior.

\subsection{Job Accessibility}

Job accessibility is an important indicator when analyzing urban form performance from a transportation perspective. Traditionally, transportation experts paid more attention to traffic engineering-related issues, such as traffic configuration, the number of intersections and connectivity of local roads, highways, railways and other transportation infrastructure [19]. Later, accessibility to job and other facilities received more research interests from both scholars and policy makers, because of the social implications for disadvantaged groups.

Accessibility can be defined as the efforts to overcome certain fictions to a pointed destination [20]. There are usually two approaches calculating accessibility: the gravity model and the accumulated opportunity model. The gravity model investigates the potential attraction between origin and destination on a TAZ level based on transportation networks [21, 22]. The accumulated opportunity model calculates the number of jobs that can be accessed within a fixed commuting time [23]. Job accessibility is not only a technical index to capture the urban form pattern and transit cost from home to the job location, but also measure the performance on job markets-especially for low-income, women, ethnic minorities and other vulnerable groups [15]. In terms of urban form, job accessibility also includes the consideration of the land-use and spatial distribution information. Currently, better accessibility is listed as the principles of good urban planning.

\section{Research Framework, Case and Method}

Previous research has mostly focused on the job-housing spatial relationship and job accessibility-related topics, while research on how rail transportation influence urban form is still rare. This paper builds its research framework on the urban form theory, focusing on the interaction between transportation, population and employment (Fig. 1). Correspondingly, this framework highlights three research questions: (1) rail transportation lead population distribution (residential space) change; (2) rail transportation lead employment distribution (economic space) change; and (3) relation between job-housing and travel behavior. By applying the methodology of TAZ-level analysis by GIS in American cities, this paper adopts street district, town and township as basic units, combined with population census data from 2000 and 2010, and basic unit economy survey data from 2001 and 2008. Transportation



Fig. 1 Research framework of "transportation-population-economy"

network data including subway and light rail are also transferred to GIS format.

This paper selects Beijing as case study. Beijing's rail transit has experienced a rapid growth, with the total number of lines increasing from 3 to 18 (including the airport link) during 2000-2015 (Fig. 2). The total length of rail traffic today amounts to $527 \mathrm{~km}$ (2015). At the same time, the job-housing spatial relationship has changed significantly from a relatively balanced job-housing integration before the economic reform, to a job-housing separation in the transition period. The Beijing metropolitan area as analyzed in this case study also includes parts of Tianjin and Hebei (Jing-Jin-Ji).

\section{Results: Urban Form Changes on Metropolitan and Urban Scale}

\subsection{Accessibility Changes in Beijing-Tianjin-Hebei Area}

Studies from countries in the West have noted that highspeed rail construction can balance the population distribution in metropolitan areas. In particular, experiences from European cities show that improvements in accessibility can encourage citizens to move from city centers to remote suburban areas [24]. Similarly in the analysis of the Beijing-Tianjin-Hebei region, although the accessibility of urban agglomeration increased significantly in the high-speed rail period, these cities might not benefit by just having rail transportation passing through.

As an important transportation infrastructure, highspeed rail significantly changes the accessibility and population distribution on a metropolitan level compared to regular rail systems. In the year of 2000, a 1-h commuting trip in any given direction would only get the citizen to the boundaries of Beijing's administrative zone and a few nearby cities southeast of Beijing (Fig. 3, left). The average travel time to all the prefectural-level cities was around 

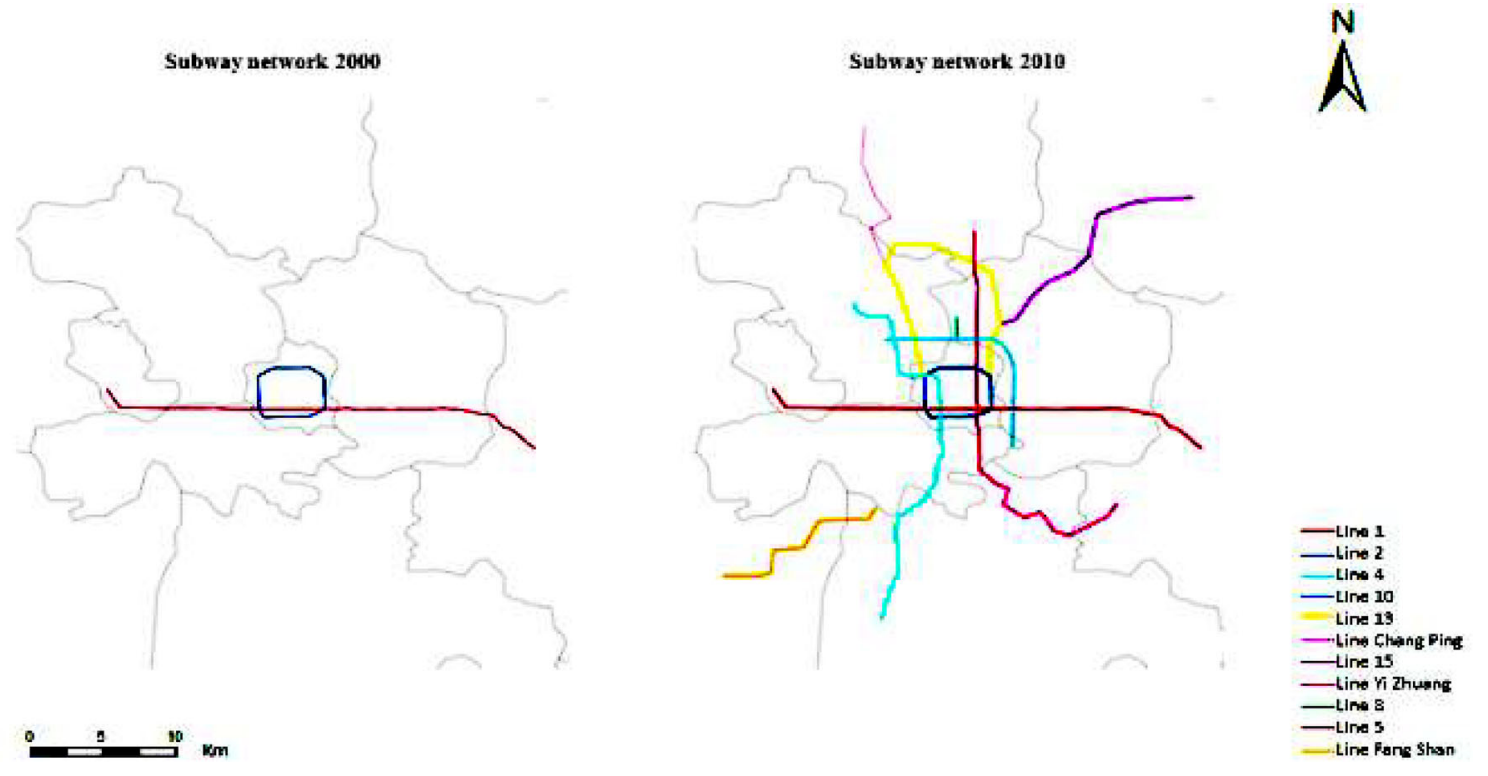

Fig. 2 Urban metro system expansion from 2000 to 2010 in Beijing metropolitan area
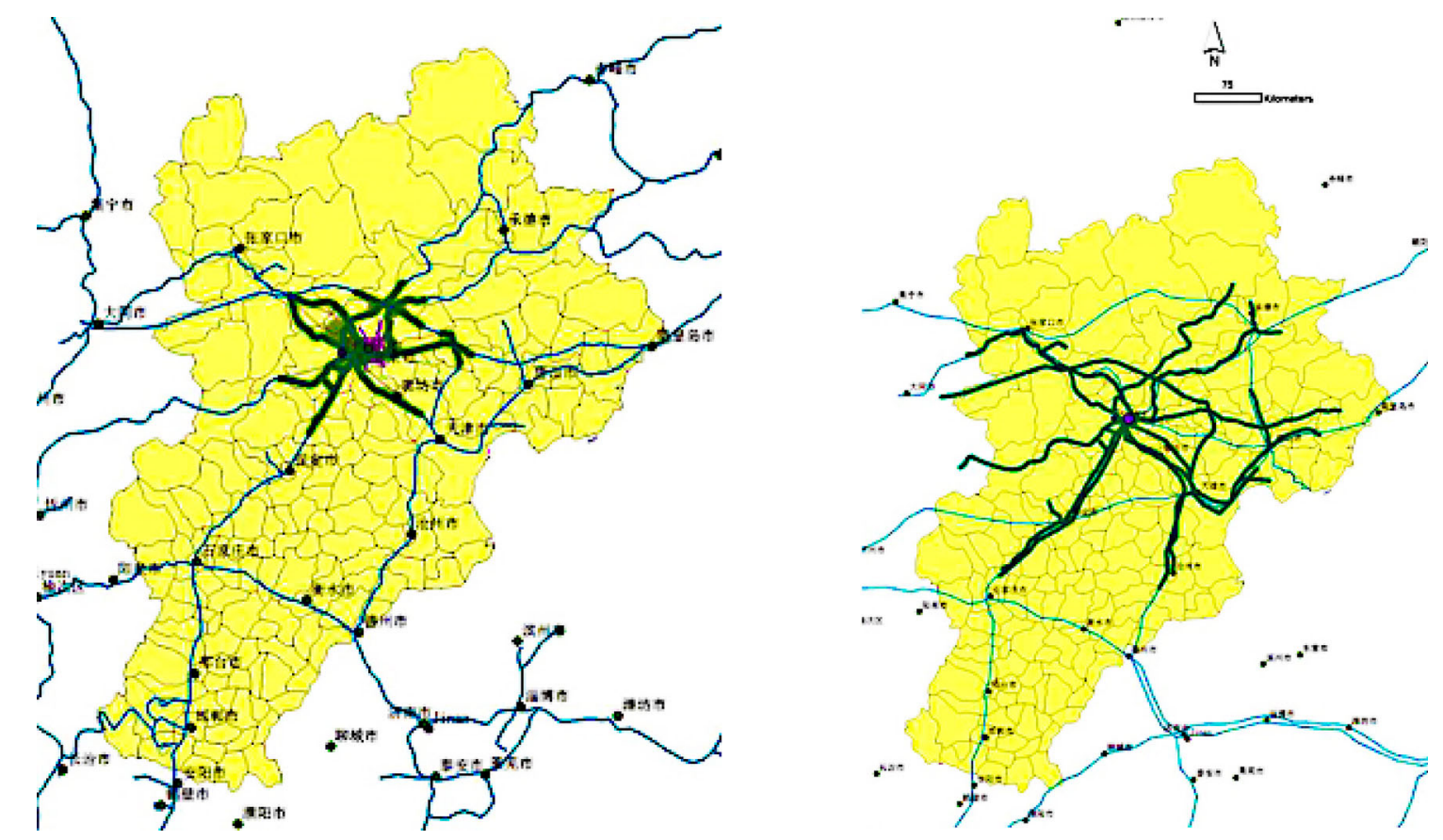

Fig. 3 Beijing Tianjin and Hebei region accessibility change from the county-level units (left) to high-speed rail (right)

3-3.5 h with regular speed trains (Fig. 3, right). In the year of 2010, after the introduction of high-speed rail lines, the 1-h commuting trip would reach five times as far and reach nine cities. Correspondingly, the average traveling time to all the prefectural-level cities is around $1-1.5 \mathrm{~h}$ in highspeed rail era. Hence, high-speed rail has clearly expanded the accessibility for commuters and greatly integrated the Beijing-Tianjin-Hebei region.
Furthermore, county-level analysis shows that cities benefit significantly from being connected to the highspeed rail network. While the traditional railway system connects counties or county-level cities and stops at most of these, the high-speed rail is only accessible from larger cities. As a consequence, smaller towns and cities are increasingly losing their connectivity advantage and turn into locations which the high-speed rail 
passes through without stopping. The accessibility on city scale depends more on the link with high-speed rail network on regional scale. In short, the changes in accessibility and population redistribution caused by high-speed rail transportation seem to further deepen the gap between the central city and its surrounding areas.

\subsection{Residential Density Change and Population Redistribution}

Studies on metropolitan scales usually indicate that citizens tend to concentrate in better accessible areas, and construction of highways and other infrastructure in suburbs usually attract more residents [16].

In our case, street district-level analysis of Beijing's metropolitan area shows that with the establishment of the urban metro system from 2000 to 2010, population distribution experienced overall dispersion and local centralization at the same time. On the one hand, there are more new subcenters emerging with the extending urban metro system (Fig. 4, left). For example, the red bar shows emerging residential centers in Tiantongyuan and Huilongguan along subway 13 and also Shuangqiao and Tongzhou New Town along subway 8 .

One the other hand, citizens became more concentrated at specific metro connection nodes, due to the improved accessibility. For example, the population density increased around Xizhimen metro station, where subway lines 2 and 4 connect, and around Huangzhuang, where subway lines 4 and 10 connect (Fig. 4, right).

The findings indicate that the impact of rail transit on population redistribution can be a double-edged sword, as it encourages suburbanization because of shorter commuting time, but also causes population concentration at transportation nodes. On urban scale with the establishment of urban rail transit system, population appears both trend of suburbanization along urban metro lines and centralization on transportation nodes.

\subsection{Job Density Change and Employment Redistribution}

While residential statistics show a twofold process of both increased suburbanization and local population concentration, employment locations also change with due to the urban metro system. Our analysis shows that the areas of employment are become more centralized, which indicates that employment centers emerge in the inner city because of better accessibility by rail transit. In particular, central business district areas tend to emerge at intersections of metro lines, such as Guomao, Fuxingmen and Zhongguancun (Fig. 5, red area). In addition, our analysis found that job density gaps are even larger in 2010 compared to 2000 , which indicates a change in location value caused by the development of the urban metro system.

Compared with the population redistribution in suburban areas, the process of job suburbanization is more unclear. Clifton et al. [7] case study in the USA suggests that employment centers move to suburban areas in tandem with transportation infrastructure construction, seeking lower land price. Furthermore, in metropolitan areas such as London, Paris and Tokyo have distinct polycentric urban patterns at different scales [25]. Compared with these western cities, urban rail transit in China plays a more important role in centralizing employment centers.

\subsection{Relationship Between the Job-Housing Balance Index and Urban Rail Transit Commuting Behavior}

While the development of urban rail transit has changed the distribution of populations and employment space, it has also had dramatic impacts on the job-housing spatial
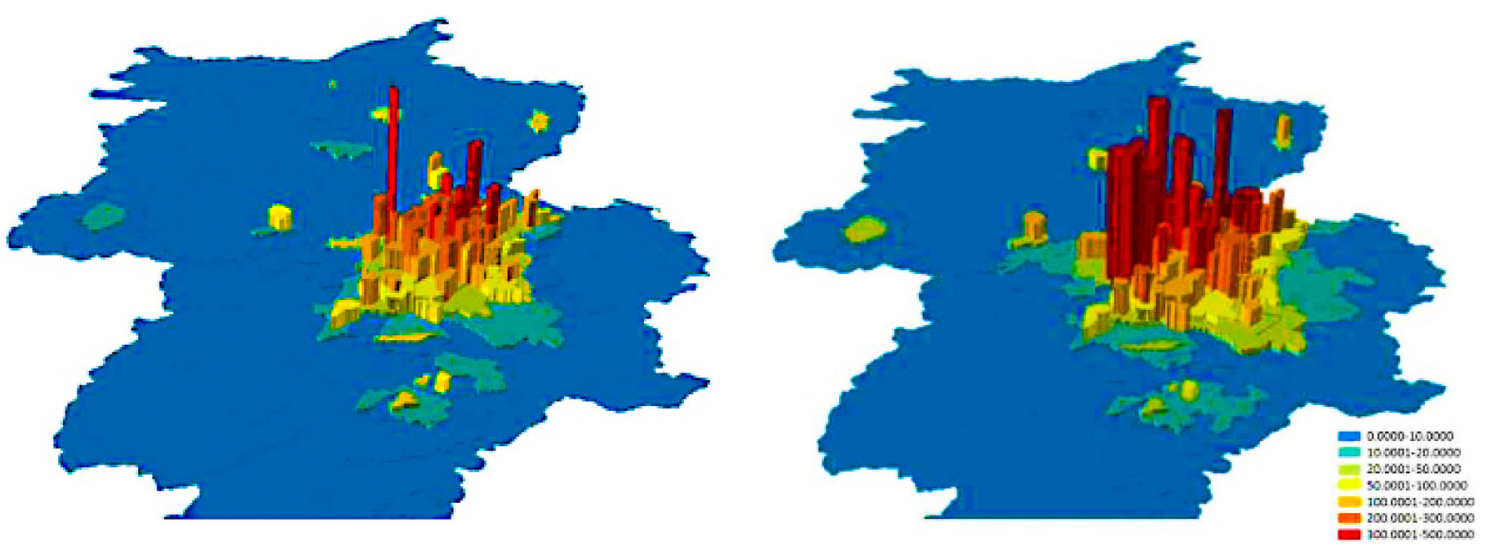

Fig. 4 Development of urban rail transit and the change in population spatial distribution (2000-2010) 

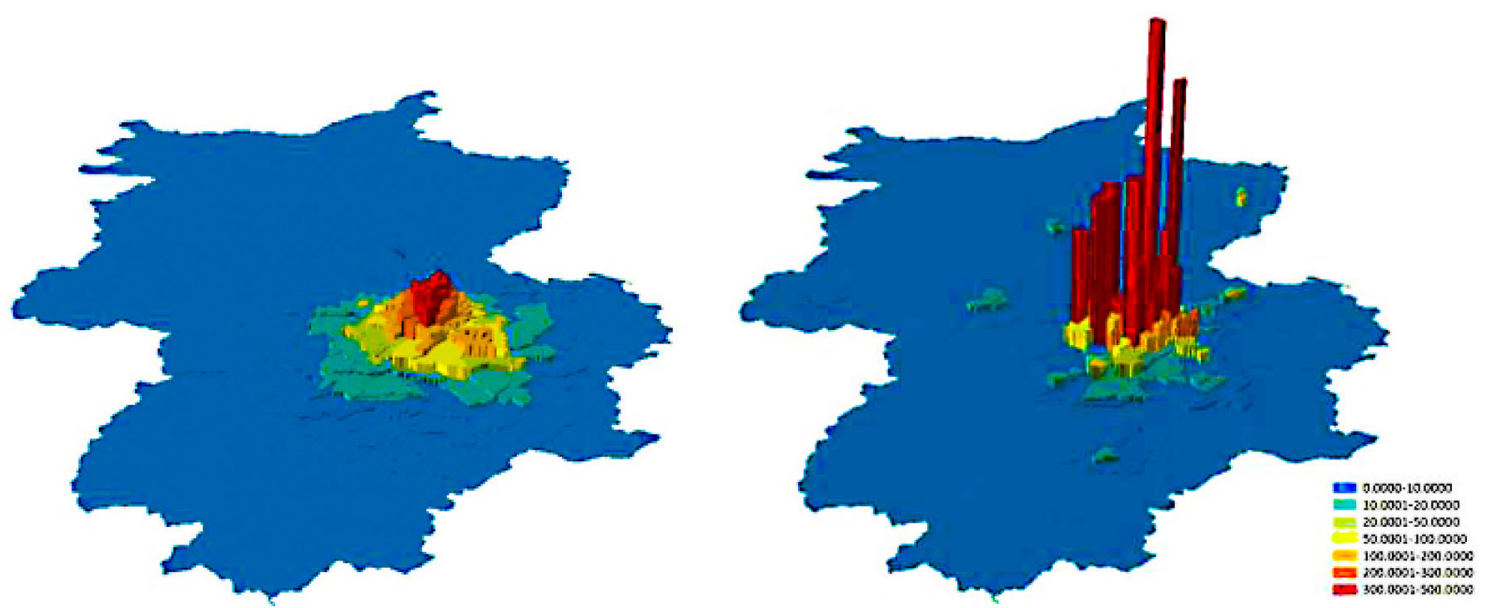

Fig. 5 Urban rail transit development and the change in employment spatial distribution (2000-2010)

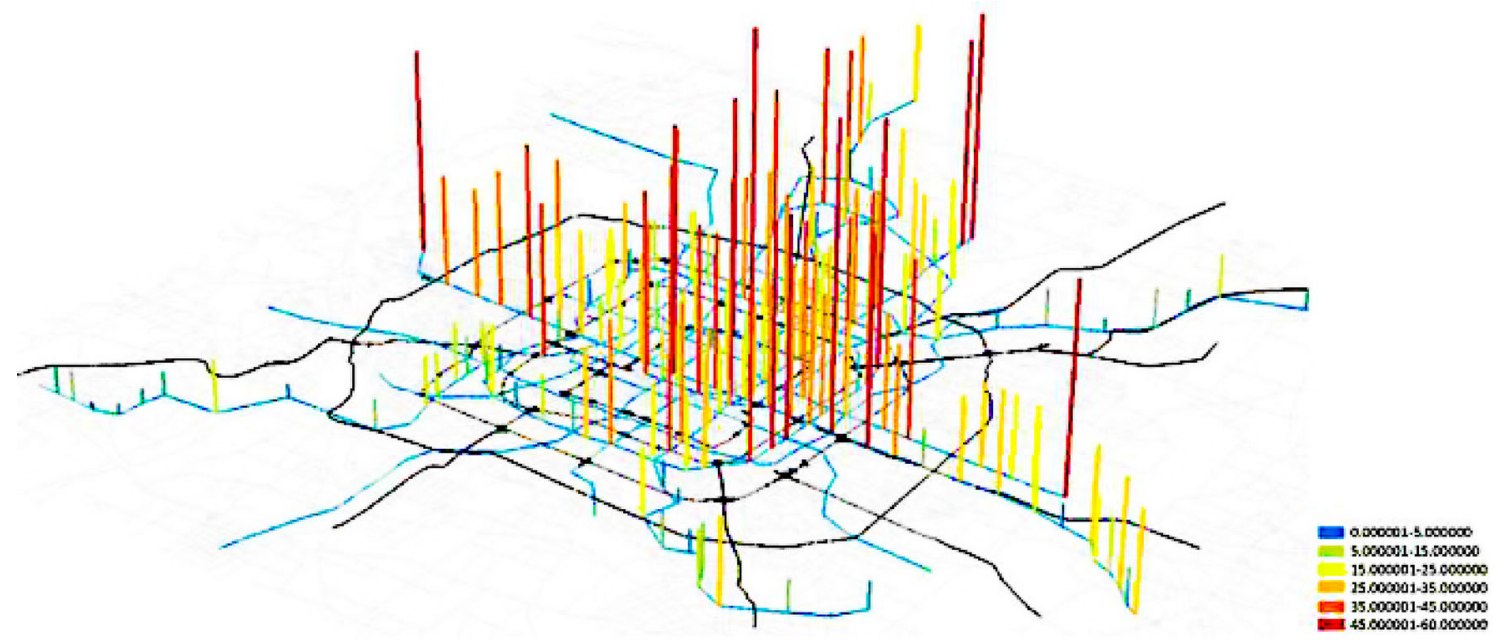

Fig. 6 Passenger volume of urban metro station in Beijing

relationship in Beijing. In terms of job-housing balance (JHB) index, it shows the job-housing mismatch pattern while the JHB index is higher in the city center area with more job opportunities, and JHB index is lower in the suburban area with more residential functions. It usually finds in the USA cities that job-housing spatial relationship has great impact on commuting behavior on metropolitan area [26]; some scholar even taken it as sin to long-distance commuting.

An analysis of the passenger flow of urban metro station shows that the commuting volume is higher in areas with an extreme job-housing mismatch. For example, a job center such as Guomao has a very high JHB index, while residential centers such as Tiantongyuan and Huilongguan score very low on the JHB index (Fig. 6). With an imbalanced job-housing relationship, the urban metro system will face heavy volume pressure locally. Our findings indicate that microlevel rail transit passenger volume of each station correlates with the job-housing spatial relationship. The policy implication for transportation planners and urban planners is that only transportation infrastructure cannot solve commuting problems, but there is a need to also consider the influence of urban form such as job-housing spatial relationships.

\section{Conclusion}

This paper explores the impact of urban rail transit on urban form by metropolitan and urban scale analysis. Based on the research framework of transportation-population-economics, findings show that the establishment of the urban metro system increased local transportation accessibility, as well as caused spatial redistribution of both 
residential and employment centers. The introduction of high-speed rail has significantly improved accessibility among cities located on the boundary of the BeijingTianjin-Hebei metropolitan area and now allows a 1-day commute within the metropolitan area.

The analysis of residential density shows that population distribution is scattered along the urban metro lines in suburban areas, and tended to concentrate around urban metro stations where metro lines connect. In terms of job density, our findings show that employment distribution becomes more centralized and the gap between urban centers and suburban areas becomes even larger.

The accumulated literature on the relation between transportation and urban form in the USA, experience the shift of research topics from transportation network configuration, job accessibility to job-housing spatial relationship in a larger scale. Currently, the research has been focus on the influence of existing urban form on travel behavior, while high-density, mixed land-use planning principals are promoted to calm down traffic. However, as its counterpart in Chinese cities, rapid urban rail transportation induces urban population and employment space redistribution, while it also induces job-housing spatial mismatch on a larger scale. While vast transportation investment promotes accessibility and provides convenience for urban residents, it also brings new transportation problems and heavier traffic pressure.

This paper shows different model in terms of urban form change under rail transportation between China and the US cities. In most American cities, it continues the job-housing mismatch pattern brought up by John Kain in the 1960s, where the urban rail transit serving as important facilities in the inner city for the urban poor. On the contrary in most Chinese cities, rail transportation mostly benefits the middle- and low-income group who lives on the urban fringe, but has to commute between employment location in the urban center and residential location in the far suburban area. With the rapid growth rail transportation system, it usually shows dynamic, interactive and complex changes on urban form, and also appears new problems, new opportunities and challenges under the unique period of mass production of urban rail in China.

Based on the analysis in this paper, future studies on the impact of urban rail transportation on urban form can add important insights on how to widen the scope of transportation planning to also include the links between population, economy and land use.

The limitation of this paper lies in that transportation is not the only reason driving urban form changes, which may occur with or without metro construction. For example, in most American cities, urban form is more shaped by highways than by urban rail transit. Future research is needed to further explore the interaction between urban form and other elements to clarify the relation between urban form and rail transportation. Besides the physical aspects of urban form, social impacts also require due attention, i.e., analyzing how the travel behavior of disadvantaged groups (such as the elderly, poor, women) is impacted by urban rail transit. The social impacts of rail transit construction contain issues relating to social equity and sustainable development. With increasing access to big data, POI data, mobile phone data, Baidu heat map and other new data sources, the relationship between rail transit and urban form is potentially a vibrant field for future research.

The will provide policy implication for promoting the healthier and more sustainable urban form, while increase job accessibility and improve job-housing balance on a larger scale, making transportation, land-use and urban planning integration in the future in rapid developing cities.

Acknowledgements Funding was provided by National Natural Science Foundation of China (Grant Nos. 41401651, 51678029), the China Fundamental Research Funds for the Central Universities (Grant No. 2016JBWZ002).

Open Access This article is distributed under the terms of the Creative Commons Attribution 4.0 International License (http://crea tivecommons.org/licenses/by/4.0/), which permits unrestricted use, distribution, and reproduction in any medium, provided you give appropriate credit to the original author(s) and the source, provide a link to the Creative Commons license, and indicate if changes were made.

\section{References}

1. Goodstadt V (2008) European perspectives on megaregions and spatial planning. In: Metropolitan area and space planning seminar, Lincoln Research Center, Peking University, Beijing

2. Pain K, Hall P (2006) People and places: interrelating the space of flows and the space of places. In: Hall P, Pain K (eds) The polycentric metropolis: learning from mega-city regions in Europe. Earthscan, London, pp 113-121

3. Hall P (2006) Firms and places: inside the mega-city regions. In: Hall P, Pain K (eds) The polycentric metropolis: Learning from mega-city regions in Europe. Earthscan, London, pp 57-94

4. Lang R, Lefurgy J, Nelson AC et al (2006) The six suburban eras of the United States research note. Opolis Int J Suburban Metrop Stud 2006(1)

5. Wang J, Lin Z (2011)The impact of high-speed railway on urban spatial evolution: an analysis based on China's characteristics [J]. Int Urban Planning 2011(1):16-23

6. Todorovich P, Schned D, Lane R (2011) High speed rail: international lessons for U.S. policy makers. Doc De Treball 76(2):537-553

7. Clifton K, Ewing R, Knaap G-J, Song Y (2008) Quantitative analysis of urban form: a multidisciplinary review. J Urban Int Res Placemak Urban Sustain 1(1):17-45

8. Frank L, Pivo G (1994) Relationships between land use and travel behavior in the Puget sound region. Single Occupant Vehicles 86(10):1361-1362

9. Cervero R (1994) Transit-based housing in California: evidence on ridership impacts. Transp Policy 1(3):174-183 
10. Messenger T, Ewing R (1996) Transit-oriented development in the sun belt. Transp Res Rec J Transp Res Board 1552(1):145-153

11. Kain JF (1968) Housing segregation, negro employment, and metropolitan decentralization. Q J Econ 82(2):175-197

12. Ellwood DT (1986) The spatial mismatch hypothesis: are there teenage jobs missing in the ghetto? In: Freeman RB, Holzer HJ (eds) The black youth employment crisis. University of Chicago Press, Chicago, pp 147-190

13. Ley D (1993) Social geography of the city. Harper \& Row Press, New York

14. Mattingly DJ (1999) Job search, social networks, and local labormarket dynamics: the case of paid household work in San Diego, California. Urban Geogr 20(1):46-74

15. Grengs $J$ (2010) Job accessibility and the modal mismatch in Detroit. J Transp Geogr 18(1):42-54

16. Weitz J, Schindler T (1997) Are Oregon's communities balanced? A test of the jobs-housing balance policy and the impact of balance on mean commute times. Unpublished manuscript, Department of Urban Studies and Planning, Portland State University

17. Hu L (2015) How does job access affect the employment outcomes of different income groups? In: Transportation Research Board annual meeting
18. Zhang C, Man J (2015) Examining job accessibility of the urban poor by urban metro and bus: a case study of Beijing. Urban Rail Transit 1(4): 183-193

19. Loutzenheiser D (1997) Pedestrian access to transit: model of walk trips and their design and urban form determinants around Bay area rapid transit stations. Transp Res Rec J Transp Res Board 1604:40-49

20. Handy SL, Niemeier DA (1997) Measuring accessibility: an exploration of issues and alternatives. Environ Plan A 29(7):1175-1194

21. Hansen WG (1959) How accessibility shapes land use. J Am Inst Plan 25(2):73-76

22. Huff DL (1963) A probabilistic analysis of shopping center trade areas. Land Econ 39(1):81-90

23. Wachs M, Kumagai TG (1973) Physical accessibility as a social indicator. Socio Econ Plan Sci 7(5):437-456

24. Vickerman R (1999) Is transport infrastructure effective? J Transp Geogr 7(3):230-231

25. Zhang C, He C (2010) Metropolitan area and spatial planning: international experience. Int Urban Plann 4:85-91

26. Boarnet M, Crane R (2001) The influence of land use on travel behavior: specification and estimation strategies. Transp Res Part A Policy Pract 35(9):823-845 